\title{
A comparative study of rubber band ligation versus BANANA-Clip in grade 1 to 3 internal hemorrhoids
}

Dong Wan Kang, Byoung Soo Kim, Ji Hun Kim, Kyong Rae Kim, Gyong Suk Kang

Department of Colorectal Surgery, Wellness Hospital, Busan, Korea

\section{Graphic Abstract}

\section{Purpose To investigate the results of the comparative treatment between rubber band ligation(RBL)}

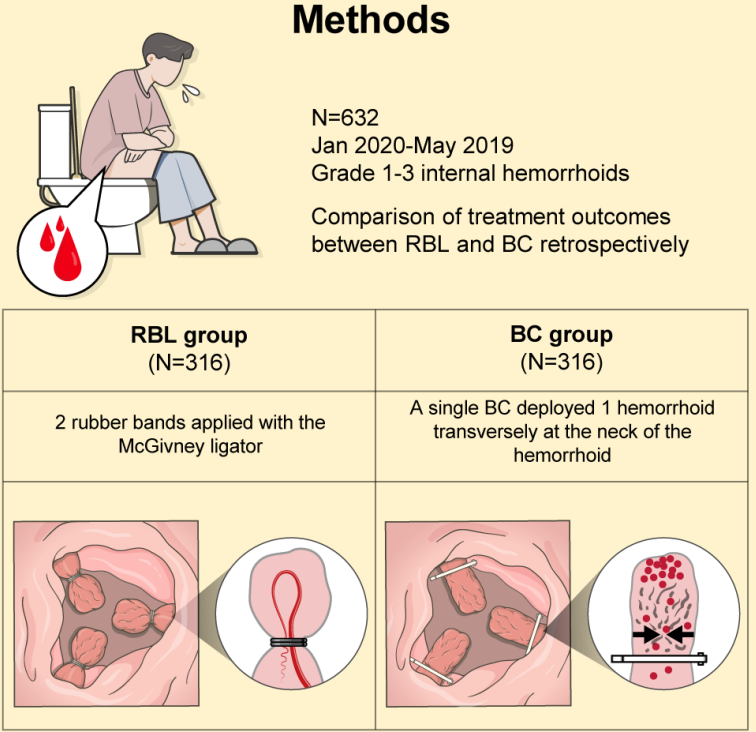

Conclusion $\mathrm{BC}$ was more reliable in treating grade 1 to 3 internal hemorrhoids with higher success rates and less delayed bleeding than RBL

No relapse at 1 year
Result

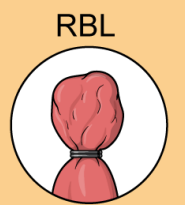

No. of ligated sites

$1.49 \pm 0.57$

BANANA-clip

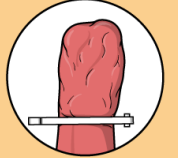

Delayed bleeding

$3.5 \%$

$0.6 \%$

thrombosis

after surgery

$95.9 \%$

Advantages of BANANA-clip

- A definite endothelial injury

$\rightarrow$ Almost no delayed bleeding, $0 \%$

- Only longitudinal constriction

$\rightarrow$ No stenosis even after 3 ligations

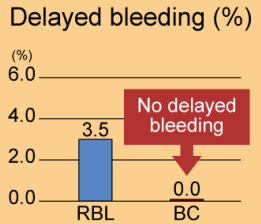

A $C$ Annals of AC Coloproctology Kang et al.
Received: Aug 10, 2021 - Revised: Sep 29, 2021 - Accepted: Oct 12, 2021 Correspondence to: Dong Wan Kang, MD, PhD

Department of Colorectal Surgery, Wellness Hospital, 52 Bansong-ro,

Yeonje-gu, Busan 47551, Korea

Email: dwkangdr58@gmail.com

ORCID: https://orcid.org/0000-0003-1214-4602

\section{(C) 2023 The Korean Society of Coloproctology}

This is an open-access article distributed under the terms of the Creative Commons Attribution NonCommercial License (https://creativecommons.org/licenses/by-nc/4.0) which permits unrestricted non-

commercial use, distribution, and reproduction in any medium, provided the original work is properly cited. 
Purpose: Rubber band ligation (RBL) for grade 1 to 3 internal hemorrhoids is a well-established modality of choice. But RBL is also a kind of surgical treatment; it is not free from complications (e.g., delayed bleeding [DB], rectal stenosis). This study aimed to investigate the results of the comparative treatment of RBL and BANANA-Clip (BC; Endovision).

Methods: Study participants were 632 consecutive patients with grade 1 to 3 internal hemorrhoids attended to Department of Colorectal Surgery at Wellness Hospital between January 2010 and May 2019. We retrospectively reviewed the incidence rate of complications, including DB between RBL and BC.

Results: There were 304 male and 328 female patients, whose ages ranged from 15 to 84 years, with a mean age of 45.7 years. The common symptom and cause of treatment was prolapse $(70.1 \%)$. The number of ligated sites was $1.49 \pm 0.57$ in the RBL group and $1.99 \pm 0.77$ in the BC group. RBL showed a significantly higher incidence of DB (3.5\%) compared to $\mathrm{BC}(0 \%)(\mathrm{P}=0.001)$. The 1 -year success rate was $95.9 \%$ in the RBL group and $99.7 \%$ in the $\mathrm{BC}$ group $(\mathrm{P}=0.005)$.

Conclusion: In our study, BC was more reliable in treating grade 1 to 3 internal hemorrhoids with higher success rates and less postligation complications, especially DB, compared to RBL.

Keywords: Hemorrhoids; Rubber band ligation; BANANA-Clip; Delayed bleeding; Vascular system injuries; Pathologic constriction

\section{INTRODUCTION}

For the treatment of the bleeding internal hemorrhoids, Blaisdell $[1,2]$ exhibited in 1954 and published in 1958 a ligation method with silk after pulling hemorrhoids through the metal drum. In 1963 and 1964, Barron [3, 4] published his innovation for ligation of internal hemorrhoids, consisting of small-caliber elastic bands designated as Latex $\mathrm{O}$ rings. For loading an elastic band on the drum, the principle by Gravlee and Jones [5] has been adopted, which was used for tying umbilical cord. Thereafter, the rubber band ligation (RBL) is widely used as an alternative method for the treatment of symptomatic internal hemorrhoids [6] and has replaced hemorrhoidectomy in $44.8 \%$ of cases [7].

Unlike hemorrhoidectomy, RBL does not destroy the perianal skin, exquisitely sensitive squamous, and transitional epithelium which reduces the risk of complications; e.g., pain, the incidence of delayed wound healing, wound stricture, and skin tag [3]. Furthermore, patients can return earlier to daily life. After RBL, the anus remains dry, and there is no need to put the gauze into the perianal area. Furthermore, it allows the destruction of internal hemorrhoids, just as in the standard ligature and excision method of hemorrhoidectomy [3]. RBL is cost-effective compared with hemorrhoidal artery ligation, stapled hemorrhoidopexy, or surgical hemorrhoidectomy [8] and doesn't alter anorectal function [9]. For this reason, RBL is recommended as the initial mode of therapy for grades 1 to 3 hemorrhoids.

But ligation of the rubber band is also a kind of surgical treatment, and it is not free from complications that may be minor or major. Self-limiting minor complications are pain, bleeding, band slippage, urinary retention. Major complications are massive, delayed bleeding (DB), severe thrombosis with pain, severe thrombosis with urinary retention. Chen et al. [10] defined DB as blood loss over $200 \mathrm{~mL}$ and Kim et al. [11] as pouring blood or blood clots over once without stool. Authors defined that DB is almost arterial and projectile with hypovolemic shock between 1 and 2 weeks after procedure which should be controlled at the operating room. In most cases, bleeding is occurred during defecation and blood is stagnated in the rectum for several hours until the patient feels to defecate. Another disadvantage of RBL is that 3 major internal hemorrhoidal piles might not be ligated in 1 ses-

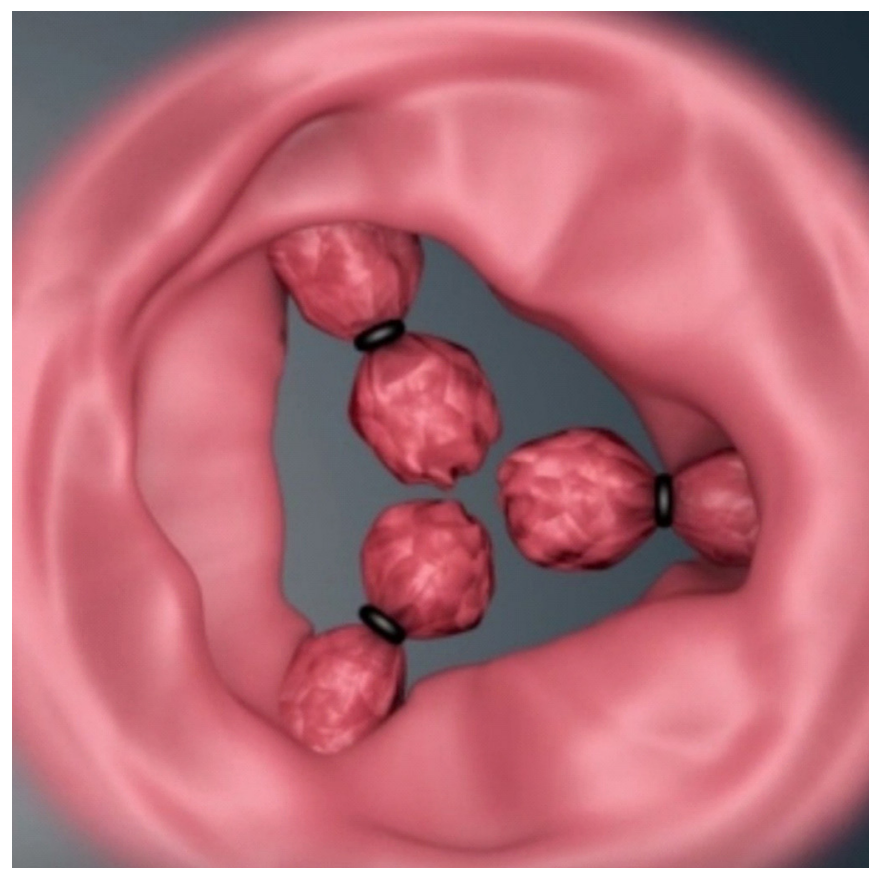

Fig. 1. Possible rectal stenosis after ligation of 3 main hemorrhoidal piles with rubber band in 1 session. 
sion because of the possibility of rectal stenosis (Fig. 1), tenesmus, or septic complication [3]. However, several authors reported that triple RBL is safe [12-14].

To reduce the incidence of the $\mathrm{DB}$ and rectal stenosis among the above-mentioned complications of the rubber band, we designed BANANA-Clip (BC; Product license No. 16-4778, BANANACLIP, BC-100; Product license No. 22-4268, BANANA-Clip, BC200; Endovision), a nonabsorbable polymer ligating clip (Fig. 2A), named from its curvilinear shape as banana, and BC is $10 \%$ longer than conventional ligating clip because hemorrhoidal tissues are larger than vessels, ducts, or sacs in other parts of the human body. And BC causes necrosis of hemorrhoidal tissue and falls off from the rectal wall in 1 or 2 weeks as rubber band. It comes out through the anal canal during defecation almost without foreign body sensation. For its angle-adjusting approach to the neck of the hemorrhoidal pile on the rectal wall through the anal canal and for deploying $\mathrm{BC}$ in the transverse direction to the anorectal axis, the head of the applier was bent to $90^{\circ}$ (Fig. 2B). The present study evaluates the results of the comparative treatment of RBL and BC.
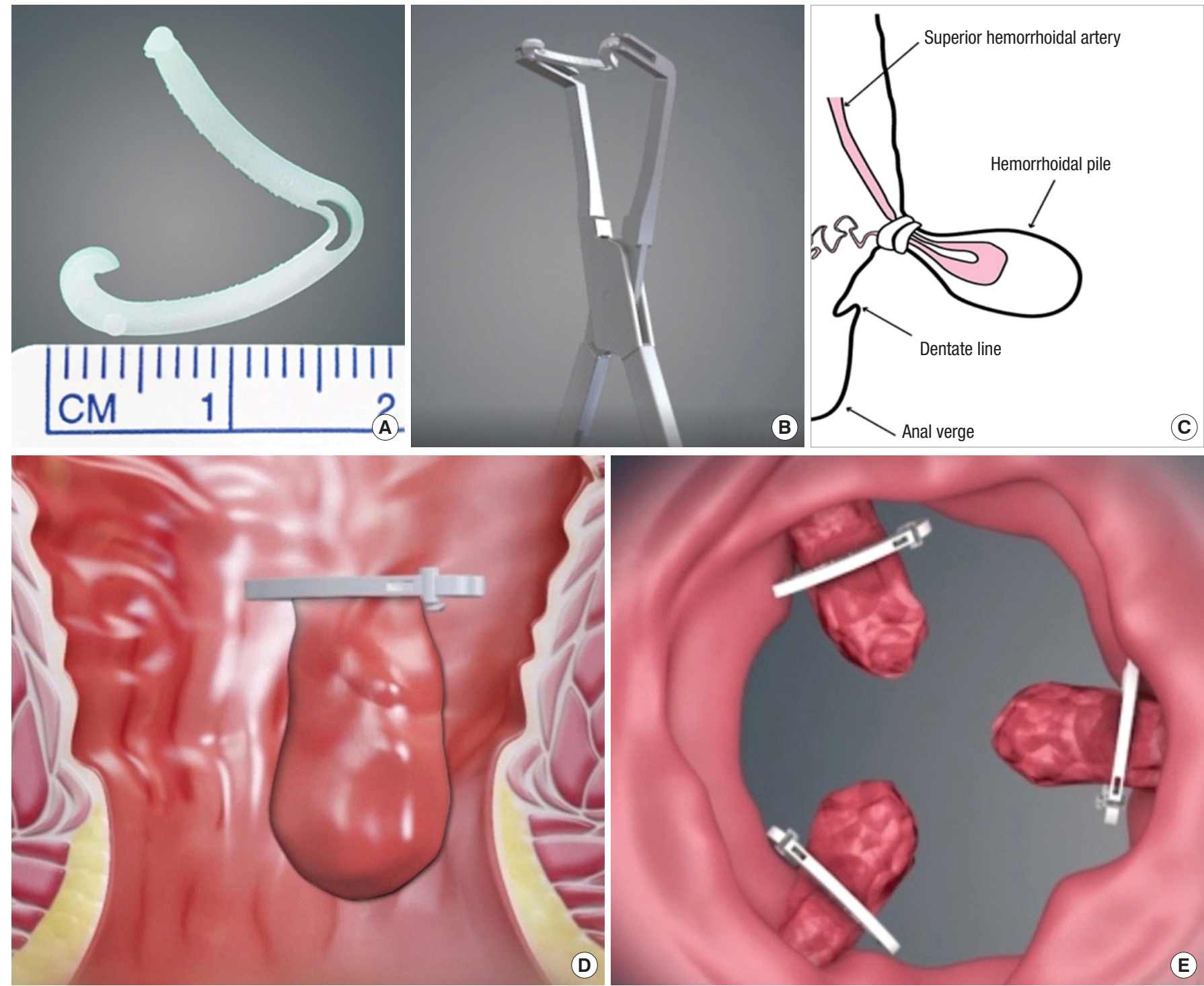

Fig. 2. (A) Curvilinear shaped BANANA-Clip (BC) which is $10 \%$ longer than conventional ligating clip (Endovision, Daegu, Korea). (B) Applier for $\mathrm{BC}$ which is bended in 90 grades at its neck part for hemorrhoid ligation (Endovision). (C) Ligated hemorrhoidal pile with 2 rubber bands, modified from Park [15] with permission of the authors. (D) Internal hemorrhoid is transversely ligated with BC (Endovision). (E) No rectal stenosis after 3 ligations of $\mathrm{BC}$ because of longitudinal constriction (Endovision). 


\section{METHODS}

\section{Ethical statements}

This study was reviewed and approved by the Korean Public In- stitutional Review Board designated by the Ministry of Health and Welfare (No. P01-202105-21-013). Written informed consent was waived due to its retrospective nature.

Table 1. The patients' baseline characteristics between groups

\begin{tabular}{|c|c|c|c|c|}
\hline Variable & Overall & $\mathrm{RBL}$ & $\mathrm{BC}$ & P-value \\
\hline No. of patients & 632 & 316 & 316 & \\
\hline Age $(y r)$ & $45.77 \pm 14.83(15-84)$ & $46.31 \pm 14.37(15-83)$ & $45.23 \pm 15.27(18-84)$ & $0.361^{\mathrm{a}}$ \\
\hline \multicolumn{5}{|l|}{ Sex } \\
\hline Male & $304(48.1)$ & $169(53.5)$ & $135(42.7)$ & $0.007^{b}$ \\
\hline Female & $328(51.9)$ & $147(46.5)$ & $181(57.3)$ & \\
\hline \multicolumn{5}{|l|}{ Main symptom and cause of treatment } \\
\hline Bleeding & $374(59.2)$ & $179(56.6)$ & $195(61.7)$ & $0.195^{b}$ \\
\hline Prolapse & $443(70.1)$ & $203(64.2)$ & $240(75.9)$ & $0.001^{\mathrm{b}}$ \\
\hline Pain & $208(32.9)$ & $85(26.9)$ & $123(38.9)$ & $0.001^{b}$ \\
\hline Pruritus & $32(5.1)$ & $17(5.4)$ & $15(4.7)$ & $0.717^{\mathrm{b}}$ \\
\hline Constipation & $47(7.4)$ & $29(9.2)$ & $18(5.7)$ & $0.095^{b}$ \\
\hline \multicolumn{5}{|l|}{ Hemorrhoids grade } \\
\hline 1 & $87(13.8)$ & $66(20.9)$ & $21(6.6)$ & $<0.001^{\mathrm{b}}$ \\
\hline 2 & $276(43.7)$ & $158(50.0)$ & $118(37.3)$ & \\
\hline 3 & $269(42.6)$ & $92(29.1)$ & $177(56.0)$ & \\
\hline \multicolumn{5}{|l|}{ Location } \\
\hline Left & $101(16.0)$ & $58(18.4)$ & $43(13.6)$ & $<0.001^{\mathrm{b}}$ \\
\hline Right anterior & $50(7.9)$ & $37(11.7)$ & $13(4.1)$ & \\
\hline Right posterior & $120(19.0)$ & $80(25.3)$ & $40(12.7)$ & \\
\hline Left+right anterior & $46(7.3)$ & $25(7.9)$ & $21(6.6)$ & \\
\hline Left+right posterior & $160(25.3)$ & $75(23.7)$ & $85(26.9)$ & \\
\hline Right anterior+posterior & $54(8.5)$ & $33(10.4)$ & $21(6.6)$ & \\
\hline Left+right anterior+right posterior & $101(16.0)$ & $8(2.5)$ & $93(29.4)$ & \\
\hline No. of ligated sites & $1.74 \pm 0.72$ & $1.49 \pm 0.57$ & $1.99 \pm 0.77$ & $<0.001^{\mathrm{a}}$ \\
\hline 1 & $268(42.4)$ & $172(54.4)$ & $96(30.4)$ & $<0.001^{\mathrm{b}}$ \\
\hline 2 & $259(41.0)$ & $132(41.8)$ & $127(40.2)$ & \\
\hline 3 & $105(16.6)$ & $12(3.8)$ & $93(29.4)$ & \\
\hline \multicolumn{5}{|l|}{ Anesthesia } \\
\hline Local & $244(38.6)$ & $192(60.8)$ & $52(16.5)$ & $<0.001^{\mathrm{b}}$ \\
\hline Spinal & $377(59.7)$ & 124 (39.2) & $253(80.1)$ & \\
\hline Not done & $11(1.7)$ & $0(0)$ & $11(3.5)$ & \\
\hline \multicolumn{5}{|l|}{ Anticoagulant } \\
\hline Yes & $34(5.4)$ & $14(4.4)$ & $20(6.3)$ & $0.290^{\mathrm{b}}$ \\
\hline No & $598(94.6)$ & $302(95.6)$ & $296(93.7)$ & \\
\hline Hemoglobin $(\mathrm{g} / \mathrm{dL})^{c}$ & $13.19 \pm 1.53(7.1-17.7)$ & $13.03 \pm 1.54(7.3-16.6)$ & $13.35 \pm 1.51(7.1-17.7)$ & $0.040^{\mathrm{a}}$ \\
\hline
\end{tabular}

Values are presented as number only, mean \pm standard deviation (range), or number (\%).

RBL, rubber band ligation; BC, BANANA-Clip (Endovision, Daegu, Korea).

P-values were derived from aindependent t-test or ${ }^{b}$ chi-square test. ${ }^{c} n=391,186,205$, respectively. 


\section{Subjects}

This is a retrospective study done on a total of 632 patients who were diagnosed to have grade 1 to 3 internal hemorrhoids attended to the Department of Colorectal Surgery at Wellness Hospital in Korea. Three hundred sixteen patients for RBL and the same number of patients for BC were enrolled consecutively between January 2010 and May 2019. There were 304 male and 328 female patients, whose ages ranged from 15 to 84 years, with a mean age of 45.7 years (Table 1 ).

Before each procedure, data on the patient's demographic variables and medical history were asked. The anus and the distal rectum of all patients were examined with the physician's index finger and anoscopy. Patients suspected of having colonic disease or patients older than 50 years had sigmoidoscopy or colonoscopy depending on the anoscopic findings. We excluded the patients with previous anal surgery, Child-Pugh classification $\mathrm{C}$ liver cirrhosis, and diabetes mellitus with hemoglobin $(\mathrm{Hb})$ Alc higher than $10 \%$ or blood coagulation disorder. Patients who took the anticoagulant tablets were taught to stop 7 days before and after the operation. There was no significant difference between 2 groups in use of anticoagulant $(\mathrm{P}=0.290)$.

\section{Methods}

$\mathrm{RBL}$ and $\mathrm{BC}$ were performed in prone jackknife positions under

Table 2. Major and minor complication and recurrence

\begin{tabular}{lccc}
\hline Variable & RBL $(\mathrm{n}=316)$ & $\mathrm{BC}(\mathrm{n}=316)$ & P-value \\
\hline Major complication & & & \\
Delayed bleeding & $11(3.5)$ & $0(0)$ & $0.001^{\mathrm{a}}$ \\
Severe thrombosis with pain & $2(0.6)$ & $1(0.3)$ & $<0.001^{\mathrm{b}}$ \\
Minor complication & & & \\
Minor pain & $6(1.9)$ & $2(0.6)$ & $0.286^{\mathrm{b}}$ \\
Minor bleeding & $4(1.3)$ & $2(0.6)$ & $0.686^{\mathrm{b}}$ \\
Band slippage & $1(0.3)$ & $1(0.3)$ & $<0.001^{\mathrm{b}}$ \\
Urinary retention & $1(0.3)$ & $1(0.3)$ & $<0.001^{\mathrm{b}}$ \\
Recurrence at 1 year after surgery & & & \\
No relapse & $303(95.9)$ & $315(99.7)$ & $0.005^{\mathrm{b}}$ \\
Bleeding & $8(2.5)$ & $1(0.3)$ & \\
Bleeding, pain & $1(0.3)$ & $0(0)$ & \\
Prolapse & $2(0.6)$ & $0(0)$ & \\
Prolapse, pain & $1(0.3)$ & $0(0)$ & \\
Pruritus & $1(0.3)$ & $0(0)$ & \\
Operative method when recurred & & & \\
RBL & $10(76.9)$ & $0(0)$ & $0.286^{\mathrm{b}}$ \\
BC & $3(23.1)$ & $1(100)$ & \\
\hline
\end{tabular}

Values are presented as number only or number (\%).

RBL, rubber band ligation; BC, BANANA-Clip (Endovision, Daegu, Korea).

$\mathrm{P}$-values were derived by ${ }^{\mathrm{a}} \mathrm{Chi}$-square test and ${ }^{\mathrm{b}} \mathrm{Fisher}$ exact test. the block (38.6\%) or spinal anesthesia (59.7\%) (Table 1). For female patients, block anesthesia was preferred because it was enough to gain the optimal operating field for the ligation. For most cases of male patients, however, spinal anesthesia was preferred to achieve operating view. According to our experience, the decision of anesthesia is important to gain the optimal operating view to preventing the incorrect ligation, which could cause the tenesmus and the slippage of band or clip. Under block anesthesia, it is often difficult to dilate the anal canal to gain optimal operating field, especially in overweighted or muscular male patients. If they are placed not more than 1 or $2 \mathrm{~cm}$ proximally from the dentate line, it can cause persistent pain for several days after the procedure. If the included hemorrhoidal mass is too small, it tends to slip and can cause thrombosed hemorrhoids.

In the RBL group, to avoid slippage, 2 rubber bands were applied for each internal hemorrhoid (Fig. 2C) [15] with the McGivney ligator after pulling the hemorrhoidal pile into the metal drum. One hemorrhoid was ligated in 1 session in 172 cases (54.4\%), and 2 hemorrhoids in 132 cases (41.8\%) were ligated in 1 session. If the 3 main hemorrhoidal piles should be ligated in 1 session (12 cases [3.8\%]), rubber bands were placed in different levels in the rectum to avoid rectal stenosis. In the BC group, a single BC was deployed for 1 hemorrhoid transversely (horizontally) to the anorectal axis at the neck of the hemorrhoid (Fig. 2D) after pulling the hemorrhoidal pile with tooth forceps through BC. In 96 patients (30.4\%) in the BC group, 1 ligation was performed, while in the remaining patients, multiple ligations were performed (2 ligations, 127 cases [40.2\%]; 3 ligations, 93 cases [29.4\%]). No stenosis occurred after 2 or $3 \mathrm{BC}$ in 1 session (Fig. 2E). The number of ligation per patient in the $\mathrm{BC}$ group $(1.99 \pm 0.77)$ is statistically higher than in the RBL group $(1.49 \pm 0.57)(\mathrm{P}<0.001)$.

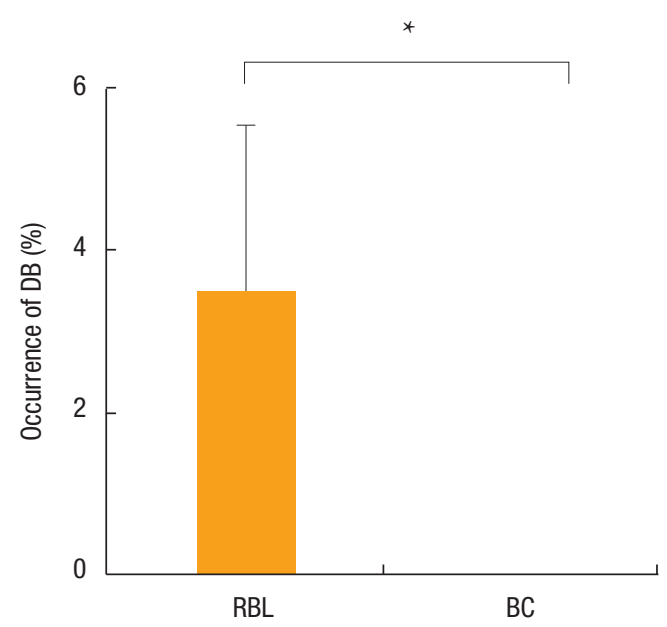

Fig. 3. Comparison of delayed bleeding (DB) occurrence between rubber band litigation (RBL) and BANANA-Clip (BC; Endovision, Daegu, Korea). Asterisk depicts the significance of difference in the incidence of DB between groups. ${ }^{*} \mathrm{P}<0.05$. 
Table 3. The summary of delayed bleeding

\begin{tabular}{lc}
\hline Variable & Delayed bleeding $(\mathrm{n}=11)$ \\
\hline Duration until delayed bleeding (day) & $13.64 \pm 4.67(7-22)$ \\
Location & $4(36.4)$ \\
Left & $1(9.1)$ \\
Left, right posterior & $2(18.2)$ \\
Right anterior & $1(9.1)$ \\
Right anterior, right posterior & $3(27.3)$ \\
Right posterior & $11(100)$ \\
Surgical treatment & $0(0)$ \\
Transfusion & $11.00 \pm 1.91(7.6-13.3)$ \\
Hemoglobin $(\mathrm{g} / \mathrm{dL})^{\mathrm{a}}$ &
\end{tabular}

Values are presented as number only, mean \pm standard deviation (range), or number (\%).

${ }^{a} n=10$.

\section{Sample size and power considerations}

The primary endpoint was the incidence of DB after treatment. Previous results indicated that the incidence of $\mathrm{DB}$ for patients who underwent RBL would be $2.45 \%$ [7] and no incidence of DB for patients who underwent BC. Based on these assumptions, a sample size of 316 patients per treatment group would provide a statistical power of at least $80 \%$ to detect a between-group difference of $2.45 \%$ at a significance level of 0.05 . nQuery+ nTerim 2.0 (Statistical Solutions Ltd) was employed for sample size calculation.

\section{Statistical analysis}

The data are presented frequency with percentage for categorical variables and mean \pm standard deviation for continuous variables. Differences in study participants' characteristics were compared across subgroups with chi-square test or Fisher exact test for categorical variables and independent test or Mann-Whitney U-test for continuous variables as appropriate. To check if its distribution is normal, we used Shapiro-Wilk test. The error bar charts were also graphically presented for data visualization. All statistical analyses were carried out using IBM SPSS ver. 26.0 (IBM Corp).

\section{RESULTS}

A total of 632 patients were included in this study who underwent hemorrhoid surgery between January 2010 and May 2018 (RBL, 316 patients; $\mathrm{BC}, 316$ patients). Mean age was 46.31 years in RBL and 45.23 years in $\mathrm{BC}$, and there was no significant difference in age $(P=0.361)$, although there was a sex difference $(P=0.007)$. The percentage of prolapse as the main cause of treatment was $64.2 \%$ (203 cases) in RBL and 75.9\% (240 cases) in the BC group $(\mathrm{P}=0.001)$ (Table 1$)$.

We classified hemorrhoids as grade 1 , if there were only bleed- ing; grade 2, if there were prolapse of the hemorrhoidal pile from the anal verge but disappear spontaneously; grade 3 , if there were prolapse but disappear by manual replacement; and grade 4 , if there were permanent prolapse. In RBL group 158 patients $(50.0 \%)$ were grade 2 and in BC group 177 patients were grade $3(56.0 \%)$. This grade difference between groups may suggest that we ligated more severe internal hemorrhoids with $\mathrm{BC}$ or more time experience. The most common location in the RBL group was right posterior $(25.3 \%)$, and in the BC group was left and right posterior (26.9\%). Ninety-three patients in the BC group (29.4\%) had 3 internal hemorrhoids, and 8 patients in the RBL group $(2.5 \%)(\mathrm{P}<$ 0.001 ) (Table 1$)$. In the RBL group, 1.49 sites $( \pm 0.57)$ per patient were ligated, which is a lower number of ligation compared to $\mathrm{El}$ Nakeeb et al. [9] $(2.35 \pm 0.49)$. In the RBL group, triple hemorrhoids were ligated by 12 patients in 1 session (3.8\%), but there was no rectal stenosis because each rubber band was ligated in different levels. Ninety-three patients (29.4\%) in the BC group underwent triple ligations in 1 session without rectal stenosis. The percentages of triple ligations in 1 session in both groups were significantly different $(\mathrm{P}<0.001)$. Spinal anesthesia was performed by 124 patients in the RBL group (39.2\%) and 253 patients in the BC group $(80.1 \%)(\mathrm{P}<0.001)$. The reason for more spinal anesthesia could be the higher grades of internal hemorrhoids in the $\mathrm{BC}$ group than in the RBL group. Fourteen patients (4.4\%) in RBL group and 20 patients (6.3\%) in BC group took anticoagulants $(\mathrm{P}=0.290)$. Hemoglobin was tested if it seemed necessary by physical examination and checked preoperative $\mathrm{Hb}$ level in RBL group was $13.03 \pm 1.54 \mathrm{~g} / \mathrm{dL}$ (186 patients [58.9\%]) and in BC group was $13.35 \pm 1.51 \mathrm{~g} / \mathrm{dL}$ (205 patients [64.9\%]) $(\mathrm{P}=0.040)$ (Table 1$)$.

A major complication, significant $\mathrm{DB}$, occurred in 11 patients (3.5\%) in the RBL group but no $\mathrm{DB}$ in the $\mathrm{BC}$ group (Table 2 ). This different result was statistically significant $(P=0.001)$ (Fig. 3). The mean duration until DB was estimated as $13.64 \pm 4.67$ days postoperation (between 7 th and 22nd days). The common bleeding site was left ( 4 cases [36.4\%]) and right posterior (3 cases [27.3\%]). However, Hwang et al. [16] reported that common sites of DB after hemorrhoidectomy for 14.062 patients were left (28 of 229 [12.2\%]) and right anterior (55 of 281 [19.6\%]) because of the inflammation and damage of wounds due to the passage of the stool in the anatomical anorectal canal. All 11 patients returned to the operating room for surgical treatment, and none of them was transfused. Ten patients checked the $\mathrm{Hb}$ from 11 (90.9\%), and its level was $11.00 \pm 1.91 \mathrm{~g} / \mathrm{dL}$ (range, 7.6-13.3 g/dL) (Table 3). But 1 patient's $\mathrm{Hb}$ was not checked because of the absence of hypovolemic shock sign. As another major complication, 2 patients $(0.6 \%)$ experienced severe thrombosis with pain in the RBL group and 1 in the BC group. All of them were treated conservatively (Table 2). Six patients experienced minor pain in the RBL group (1.9\%) and 2 patients $(0.6 \%)$ in the BC group without statistical significance. In the RBL group, 4 minor bleedings (1.3\%), 1 band slippage $(0.3 \%)$, and 1 urinary retention occurred. In BC group, 2 minor bleedings ( $0.6 \%), 1$ band slippage $(0.3 \%)$ and 1 urinary retention 
$(0.3 \%)$ occurred. These minor complications showed no statistical significance between the 2 groups (Table 2).

In the RBL group, the 1-year success rate was $95.9 \%$, and in the BC group, $99.7 \%$. This difference showed statistical significance $(\mathrm{P}=0.005)$. Komborozos et al. [17] reported that 392 patients out of $445(88.1 \%)$ were asymptomatic 2 years after RBL. By the recurrence, in the RBL group, 10 patients (76.9\%) were treated with RBL again and 3 patients (23.1\%) with BC. One patient in the BC group who presented with rectal bleeding was treated with $\mathrm{BC}$ again.

\section{DISCUSSION}

Since Blaisdell and Barron, RBL is a widely used procedure for the treatment of bleeding and/or prolapsing hemorrhoids, RBL is a different treatment compared to conventional hemorrhoidectomy because RBL preserves the sensitive perianal skin and anoderm with transitional zone and removes only the internal hemorrhoidal pile, which is the main target of hemorrhoidal treatment. RBL allows the destruction of internal hemorrhoids just as in the standard ligature and excision [3], reduces postoperative pain, risk of stricture and anal deformity, and allows the patient to return to normal life earlier. Despite these advantages, complications of RBL are possible because it is also a kind of surgical modality. Its complications are DB, pain, urinary distension, slippage of rubber bands, painful thrombosis, and vasovagal symptoms [9]. Furthermore, the 3 main hemorrhoidal piles could not be ligated with rubber bands in 1 session because of the risk of rectal stenosis or tenesmus. Barron recommended limiting the ligation to 1 internal hemorrhoid in 1 session to avoid tenesmus, especially in patients with large internal hemorrhoids and those who had previously undergone hemorrhoid surgery and injections [3]. According to our experience, the decision of anesthesia is important to gain the optimal operating view to prevent incorrect ligation, which could cause the tenesmus and the slippage of band or clip. More spinal anesthesia could be the reason of higher grades of internal hemorrhoids in the $\mathrm{BC}$ group than in the RBL group.

We designed $\mathrm{BC}$ in curvilinear style to reduce the risk of rectal stenosis or tenesmus even after ligations of 3 hemorrhoids in a single session. This shape, different from O-ring shaped rubber band, can prevent rectal stenosis even after deploying 3 or more $\mathrm{BC}$ in 1 session because it constricts hemorrhoidal tissue only longitudinally (vertically) to the anorectal axis. In this study, 93 patients (29.4\%) were treated with triple BC in 1 session, with no rectal stenosis (Fig. 2E). Therefore, there is no need for a 2nd session for remnant hemorrhoids in the case of BC. Furthermore, this functions as a lift-up of the redundant anoderm and perianal skin. In RBL group, per patient 1.49 sites $( \pm 0.57$ ) were ligated to avoid the possible rectal stenosis which is a lower number of ligation compared to El Nakeeb et al. [9] (2.35 \pm 0.49$)$.

DB after anal surgery in 1 or 2 weeks is a very significant complication for proctologists because it is not rare and sometimes very critical. In this study, the common bleeding site was left (4 cases [36.4\%]) and right posterior (3 cases [27.3\%]). However, Hwang et al. [16] reported that common sites of DB after hemorrhoidectomy for 14.062 patients were left (28 of 229 [12.2\%]) and right anterior (55 of 281 [19.6\%]) because of the inflammation and damage of wounds due to the passage of the stool in the anatomical anorectal canal. If $\mathrm{DB}$ occurs by a patient who lives in a rural area, it may be more crucial because no proctologist can care for this kind of complication. DB cannot be prevented $[9,17]$ and might be more often after RBL $(2.2 \%-4.13 \%)[7,9,17,18]$ than after hemorrhoidectomy $(0.6 \%-1.4 \%)$ [19-21]. The reason for this difference might be the tightness of the suture or ligating material. In contrast to suture material by hemorrhoidectomy, the rubber band is soft and elastic, so that it is not a reliable material to make a vascular injury of the hemorrhoidal artery. Furthermore, the soft tissue inside of rubber band functions as a buffer which might reduce the opportunity for vascular injury after ligation of rubber band. On vascular injury, especially on an endothelial injury [22], tissue factor and collagen are exposed, platelets adhere to the injury site; usually, the denuded vascular intimal site and platelets form platelet plug [23-25]. Furthermore, vasoconstriction occurs in response to releasing vasoactive substances from platelets (e.g., thromboxane A2 and serotonin) and endothelin from endothelial cells. Thromboxane A2 is produced locally at the injury site and is a very potent constrictor of smooth muscles, especially in smaller and medium-sized vessels [23] (e.g., hemorrhoidal artery). To reduce the incidence of DB after RBL, we formulated a hypothesis from the above-mentioned hemostatic theory that vascular injury might be essential to activate hemostatic sequence to prevent arterial bleeding at the moment of falling the necrotic hemorrhoidal pile. From this hypothesis, tight BC, composed of non-absorbable polymer, was designed to squeeze hemorrhoidal soft tissue and hemorrhoidal artery evenly and definitively. And BC causes necrosis of hemorrhoidal tissue and falls off from the rectal wall in 1 or 2 weeks as rubber band. It comes out through the anal canal during defecation almost without foreign body sensation. There was no case of $\mathrm{DB}$ in the $\mathrm{BC}$ group. The well-known causes of DB are local inflammation, local trauma, and the fall of hemorrhoidal nodules $[9,16,26]$. In cases of DB after hemorrhoidectomy, Hwang et al. [16] reported that proctologists after over 500 hemorrhoidectomies showed a significantly lower incidence of $\mathrm{DB}(0.54 \%)$ than proctologists before 500 hemorrhoidectomies $(1.32 \%)(\mathrm{P}<0.01)$. This result could be interpreted that the skill of the experienced surgeon to perform ligation after dissection of hemorrhoidal tissue could be more secure and definitive to make vascular injury. We carefully suggest the lack of vascular injury due to the elasticity of rubber bands as a possible cause of DB based on our results and current understanding of hemostasis. We recognize that this study has limitation. This is a retrospective observational study on a descriptive and exploratory purpose. Unfortunately, we could not perform logistic regression analysis as a multivariable analysis since no DB was 
observed in BC group. Further study with a larger number of patients will be required to adjust for other covariates such as anesthesia method. However, based on this study, it is expected to be basis for conducting a study on the BC, especially in aspect of DB and stenosis.

The findings of this study conclude that $\mathrm{BC}$ compared to RBL was found to have significantly less incidence of DB and to be a safe modality. Although the risk of stenosis after triple ligation in both groups showed no significant difference, there might be less risk of stenosis in the $\mathrm{BC}$ group, based on longitudinal (vertical) constriction to anorectal axis of $\mathrm{BC}$. The success rate of the $\mathrm{BC}$ group was higher than RBL. Thus, ligation of hemorrhoidal pile performed using $\mathrm{BC}$ is carefully recommended as an alternative method for grade 1 to 3 internal hemorrhoids. Further studies specifically comparing rubber band versus $\mathrm{BC}$ are needed to identify the better approach to reduce complications in patients undergoing ligations of internal hemorrhoids.

\section{CONFLICT OF INTEREST}

No potential conflict of interest relevant to this article was reported.

\section{FUNDING}

None.

\section{ACKNOWLEDGMENTS}

The authors thank Endovision for actively producing BANANAClip in accordance with our idea, Ms. Byeon Tae Joo for collecting detailed medical records, and Dr. Jimin Choi for conducting the professional statistical analyses.

\section{AUTHOR CONTRIBUTIONS}

Conceptualization: all authors; Data curation: all authors; Writing-original draft: all authors; Writing-review \& editing: all authors. All authors read and approved the final manuscript.

\section{REFERENCES}

1. Blaisdell PC. Scientific exhibit. American Medical Association; 1954

2. BlaisdelL PC. Office ligation of internal hemorrhoids. Am J Surg 1958;96:401-4.

3. Barron J. Office ligation of internal hemorrhoids. Am J Surg 1963; 105:563-70.

4. Barron J, Fallis LS. Non-operative treatment of internal hemorrhoids. Can Med Assoc J 1964;90:910-4.

5. Gravlee LC, Jones WN. Automatic device for tying the umbilical cord. Obstet Gynecol 1960;15:43-6.
6. Song SG, Kim SH. Optimal treatment of symptomatic hemorrhoids. J Korean Soc Coloproctol 2011;27:277-81.

7. Bleday R, Pena JP, Rothenberger DA, Goldberg SM, Buls JG. Symptomatic hemorrhoids: current incidence and complications of operative therapy. Dis Colon Rectum 1992;35:477-81.

8. Coughlin OP, Wright ME, Thorson AG, Ternent CA. Hemorrhoid banding: a cost-effectiveness analysis. Dis Colon Rectum 2019;62: 1085-94.

9. El Nakeeb AM, Fikry AA, Omar WH, Fouda EM, El Metwally TA, Ghazy HE, et al. Rubber band ligation for 750 cases of symptomatic hemorrhoids out of 2200 cases. World J Gastroenterol 2008;14:6525-30.

10. Chen HH, Wang JY, Changchien CR, Chen JS, Hsu KC, Chiang $\mathrm{JM}$, et al. Risk factors associated with posthemorrhoidectomy secondary hemorrhage: a single-institution prospective study of 4,880 consecutive closed hemorrhoidectomies. Dis Colon Rectum 2002;45:1096-9.

11. Kim HS, Lim SW, Oh JH, Lee JK, Secondary bleeding after hemorrhoidectomy. J Korean Surg Soc 1993;44:279-84.

12. Salati SA. Rubber band ligation of internal hemorrhoids: a study. Singap J Sci Res 2019;9:20-5.

13. Law WL, Chu KW. Triple rubber band ligation for hemorrhoids: prospective, randomized trial of use of local anesthetic injection. Dis Colon Rectum 1999;42:363-6.

14. Lee HH, Spencer RJ, Beart RW Jr. Multiple hemorrhoidal bandings in a single session. Dis Colon Rectum 1994;37:37-41.

15. Park JG. Coloproctology. 4th ed. Seoul: Inchokak; 2012.

16. Hwang DY, Kim YJ, Chung JE, Lee JH, Chang HC, Rhu JH, et al. Analysis of factors influencing secondary bleeding after hemorrhoidectomy. J Korean Soc Coloproctol 2002;18:369-72.

17. Komborozos VA, Skrekas GJ, Pissiotis CA. Rubber band ligation of symptomatic internal hemorrhoids: results of 500 cases. Dig Surg 2000;17:71-6.

18. Park HD, Jun SH. The rubber band ligation for bleeding hemorrhoids. J Korean Soc Coloproctol 1991;7:51-6.

19. Khubchandani IT. Operative hemorrhoidectomy. Surg Clin North Am 1988;68:1411-6.

20. Rosen L, Sipe P, Stasik JJ, Riether RD, Trimpi HD. Outcome of delayed hemorrhage following surgical hemorrhoidectomy. Dis Colon Rectum 1993;36:743-6.

21. McConnell JC, Khubchandani IT. Long-term follow-up of closed hemorrhoidectomy. Dis Colon Rectum 1983;26:797-9.

22. Despopoulos A, Silbernagl S. Color atlas of physiology. 4th ed. Thieme Medical Publishers; 1991.

23. Rutherford EJ, Brecher ME, Fakhry SM, Sheldon GF. Hematologic principles in surgery. In: Townsend Jr. CM, Beauchamp RD, Evers BM, Mattox KL, editors. Sabiston textbook of surgery: the biological basis of modern surgical practice. 18th ed. Saunders; 2008. p. 114-5.

24. Konkle BA. Bleeding and thrombosis. In: Kasper DL, Fauci AS, Hauser SL, Longo DL, Jameson JL, Loscalzo J, editors. Harrison's principles of internal medicine. 19th ed. McGraw-Hill Education; 
2015. p. 400-6.

25. Gale AJ. Continuing education course \#2: current understanding of hemostasis. Toxicol Pathol 2011;39:273-80.
26. Kunitake H, Poylin V. Complications following anorectal surgery. Clin Colon Rectal Surg 2016;29:14-21. 